\title{
Detection of Peptostreptococcus micros DNA in clinical samples by PCR
}

\author{
M. P. RIGGIO, A. LENNON and A. SMITH \\ Infection Research Group, University of Glasgow Dental School, 378 Sauchiehall Street, Glasgow G2 3JZ
}

\begin{abstract}
Peptostreptococcus micros is a gram-positive anaerobic coccus which, although considered to be a natural commensal of the human oral cavity, is associated with periodontal, endodontal and peritonsillar infections. Identification of the organism has to date relied upon conventional culture methods and biochemical analyses. The purpose of this study was to develop a PCR method for rapid and specific identification of this organism in clinical samples. A pair of primers was selected, each of which was specific at the $3^{\prime}$ end for $P$. micros DNA; they were used in the PCR assay, resulting in a 1074-bp product. The primers were shown to be specific for $P$. micros DNA as no PCR products were obtained when genomic DNA extracts from a wide range of other Peptostreptococcus species and other oral bacteria were used as templates. The PCR assay was then applied to the identification of $P$. micros DNA in subgingival plaque samples from adult periodontitis patients and pus samples from subjects with acute dento-alveolar abscesses. Confirmation of specific amplification of $P$. micros DNA was obtained by digestion of PCR products with the restriction endonuclease $R s a I$, which gives a unique restriction profile for $P$. micros, and DNA sequencing. Sixty-eight subgingival plaque samples from 18 patients were analysed, of which $19(28 \%)$ were positive for $P$. micros DNA; the proportion of patients carrying $P$. micros DNA in at least one sampled site was $11(61 \%)$ of 18. Twenty (71\%) of 28 pus samples analysed by PCR contained $P$. micros DNA. These results confirm that $P$. micros may be involved in the aetiology of acute dentoalveolar abscesses and adult periodontitis. The PCR assay provides a more rapid and reliable alternative to conventional methods for identification of $P$. micros in clinical samples.
\end{abstract}

\section{Introduction}

Peptostreptococcus micros is a gram-positive anaerobic coccus which is primarily found in the human oral cavity [1]. The organism is considered to be a commensal of the oral cavity, as it comprises $<3 \%$ of the subgingival flora in periodontally healthy adults [2]. However, it has been isolated more frequently and in higher numbers from patients with periodontitis and has been shown to be associated with periodontal destruction, particularly in periodontal sites from disease-active patients [3-5]. P. micros is also a known pathogen in other mixed anaerobic infections of the oral cavity, including endodontic abscesses [6,7], periodontal abscesses [8] and peritonsillar infections

Received 5 July 2000; revised manuscript accepted 5 Sept. 2000.

Corresponding author: Dr M.P. Riggio.
[9]. It is also often involved in severe mixed anaerobic infections throughout the human body. These include infections of the ear, sinuses and gynaecological tract [10], prosthetic joint infections [11] and abdominal abscesses [12]. However, the true extent of its pathogenic nature remains to be determined. P. micros exists as three morphotypes (smooth, rough and smooth variant of the rough type) which differ in the nature of their surface structures, with the rough type possessing large fibrillar surface structures that are absent in the other morphotypes $[13,14]$.

To date, identification of $P$. micros in clinical samples has been achieved principally by the use of bacterial culture coupled to biochemical tests, and serological methods. A selective and differential medium for the primary isolation of $P$. micros has been described [15]. Monoclonal antibodies (MAbs) recognising specific surface antigens of $P$. micros have been generated and successfully applied to its detection in clinical samples in an indirect immunofluorescence assay [16]. How- 
ever, no molecular methods have been described for detection of this organism in clinical samples.

The purpose of this study was to develop a novel PCRbased method for the detection of P. micros in clinical samples as an alternative to currently used conventional methods. Although conventional detection methods such as bacterial culture and serology have been used successfully for $P$. micros detection, they are timeconsuming and expensive and can give rise to ambiguous results. Furthermore, MAbs directed against P. micros are not readily available. An earlier study showed PCR to be more sensitive and specific than culture methods for detection of periodontal pathogens in subgingival plaque [17]. The present study describes the development of PCR primers specific for P. micros and their application in a PCR assay for detection of this organism in both subgingival plaque from adult periodontitis patients and in pus aspirates from acute dento-alveolar abscesses.

\section{Materials and methods}

\section{Bacterial culture and genomic DNA purification}

P. micros ATCC 33270 was inoculated on to Fastidious Anaerobe Agar (Life Technologies, Paisley) supplemented with defibrinated horse blood $7.5 \% \mathrm{v} / \mathrm{v}$ and incubated at $37^{\circ} \mathrm{C}$ for $4-5$ days in an anaerobic chamber (Don Whitley Scientific, Shipley) with an atmosphere of $\mathrm{N}_{2} \quad 85 \%, \mathrm{CO}_{2} \quad 10 \%$ and $\mathrm{H}_{2} \quad 5 \%$. Bacterial growth was harvested from the plates and genomic DNA was extracted with the Puregene DNA Purification Kit (Flowgen, Ashby de la Zouch) according to the manufacturer's instructions.

\section{Sample collection and preparation}

Archival subgingival plaque samples were analysed. Previously, the samples had been collected in sterile tubes containing $0.5 \mathrm{ml}$ of freshly prepared Fastidious Anaerobe Broth (Bioconnections, Leeds, W. Yorks) using a single stroke of a separate sterile curette for each sample to prevent cross-contamination. Samples were vortex mixed for $30 \mathrm{~s}$ and lysates were prepared for use in PCR by adding $3 \mu \mathrm{l}$ of achromopeptidase $(20 \mathrm{U} / \mu \mathrm{l}$ in $10 \mathrm{~mm}$ Tris-HCl, $1 \mathrm{mM}$ EDTA, pH 7.0) to $100 \mu \mathrm{l}$ of vortex mixed subgingival plaque. Samples were then incubated at $56^{\circ} \mathrm{C}$ for $30 \mathrm{~min}$, boiled for $5 \mathrm{~min}$ and stored at $-70^{\circ} \mathrm{C}$ until required.

Archival pus aspirates previously obtained from patients with acute dento-alveolar abscesses were analysed. Samples of pus $(50 \mu \mathrm{l})$ were diluted 10-100-fold in PCR diluent (10 mM Tris-HCl, $\mathrm{pH} 8.0,10 \mathrm{mM} \mathrm{NaCl}$, $1 \mathrm{mM}$ EDTA). SDS $10 \%(30 \mu \mathrm{l})$ and proteinase $\mathrm{K}(3 \mu \mathrm{l}$ at $10 \mathrm{mg} / \mathrm{ml}$ ) were added to $300 \mu \mathrm{l}$ of diluted pus and incubated at $55^{\circ} \mathrm{C}$ for $3 \mathrm{~h}$. Lysates were extracted twice with an equal volume of phenol:chloroform $(1: 1)$ and once with an equal volume of chloroform:isoamyl alcohol (24:1). DNA was precipitated by addition of 0.1 volume of $3 \mathrm{M}$ sodium acetate, $\mathrm{pH} 5.3$, and 2 volumes of ethanol $100 \%$, mixing and holding at $-70^{\circ} \mathrm{C}$ for $30 \mathrm{~min}$. DNA was collected by microcentrifugation and the dried pellet was resuspended in $100 \mu \mathrm{l}$ of sterile molecular biology grade water.

\section{Sample details}

For subgingival plaque analysis, subjects were untreated patients with chronic inflammatory adult periodontitis who were newly referred to Glasgow Dental Hospital. Criteria for use of patient samples in the study were the presence of at least three periodontal pockets with a minimum depth of $5 \mathrm{~mm}$ and bleeding on probing, coupled with no history of antibiotic treatment in the preceding 6 months. A total of 68 samples from 18 patients was analysed. The mean pocket depth of samples analysed was $7.1 \mathrm{~mm}$ (range $5-11 \mathrm{~mm}$ ); the age range of the patients was 32-60 years with a mean age of 43.6 years. Also, 28 pus samples were analysed from 28 patients, whose age range was $30-56$ years with a mean age of 41.8 years.

\section{PCR primer selection}

Primers for use in the $P$. micros PCR assay were selected by alignment of the $16 \mathrm{~S}$ ribosomal RNA (rRNA) gene sequences of members of the Peptostreptococcus genus and of several other oral bacteria. Two primers were selected from the 16S rRNA gene sequence of $P$. micros ATCC 33270 that were sufficiently unique in sequence at their $3^{\prime}$ ends, compared with the corresponding regions of all other 16S rRNA genes analysed, to confidently predict their specificity for $P$. micros DNA. The P. micros $16 \mathrm{~S}$ rRNA primers selected were 5'-TCG AAC GTG ATT TTT GTG GA-3' (Pmic-1; base position 55-74) and 5'TCC AGA GTT CCC ACC TCT-3' (Pmic-2; base position 1128-1109), which yield an expected amplification product of $1074 \mathrm{bp}$.

\section{$P C R$}

The PCR reaction mixture used was essentially as described previously [17]. Each PCR reaction mixture comprised either $5 \mu \mathrm{l}$ of plaque sample lysate or $1 \mu \mathrm{l}$ of bacterial genomic DNA and either 95 or $99 \mu 1$, respectively, of reaction mixture that contained $\mathrm{MgCl}_{2}$ at the optimal concentration of $1.5 \mathrm{mM}$. PCR cycling conditions comprised an initial denaturation step of $94^{\circ} \mathrm{C}$ for $5 \mathrm{~min}$, followed by 35 cycles of denaturation at $94^{\circ} \mathrm{C}$ for $1 \mathrm{~min}$, primer annealing at $55^{\circ} \mathrm{C}$ for $1 \mathrm{~min}$ and extension at $72^{\circ} \mathrm{C}$ for $1.5 \mathrm{~min}$, and then a final extension step at $72^{\circ} \mathrm{C}$ for $10 \mathrm{~min}$.

Stringent anti-contamination procedures were employed when performing PCR, as described previously [17]. For each batch of samples being analysed, negative and positive controls were included. The positive control 
used was a standard PCR reaction mixture containing $100 \mathrm{ng}$ of $P$. micros genomic DNA instead of sample, whereas the negative control contained sterile water instead of sample. PCR products were visualised after electrophoresis on agarose $2 \%$ gels as described previously [17].

\section{Restriction endonuclease digestion of PCR products}

PCR products were purified with the Wizard PCR Purification Kit (Promega) in accordance with the manufacturer's instructions. Briefly, $0.5 \mu \mathrm{g}$ of purified DNA was separately digested in a total volume of $20 \mu \mathrm{l}$ with 5.0 units of each of the restriction endonucleases Rsa I and HinfI (Promega) at $37^{\circ} \mathrm{C}$ for $3 \mathrm{~h}$. Restriction fragments generated were visualised by agarose gel electrophoresis.

\section{DNA sequencing}

PCR products were cloned into the pCR2.1-TOPO vector with the TOPO TA Cloning Kit (Invitrogen BV, Groningen, The Netherlands) in accordance with the manufacturer's instructions. Plasmid DNA from recombinant clones was purified with the Wizard Plus Minipreps DNA Purification System (Promega). Sequencing reactions were performed with Thermo Sequenase Fluorescent Labelled Primer Cycle Sequencing Kit with 7-deaza-dGTP (Amersham Pharmacia Biotech, Little Chalfont, Bucks) and IRD800-labelled M13 universal (-21) primer. Sequence data was collected and analysed in an automated DNA sequencing system.

\section{Results}

\section{Sensitivity and specificity of the P. micros PCR} assay

After a single round of 35 cycles of amplification, the lower limit of detection of $P$. micros DNA was $50 \mathrm{fg}$ or c. 50 bacterial cells (data not shown). To confirm the specificity of the P. micros PCR assay, $100 \mathrm{ng}$ of genomic DNA from each of the following Peptostreptococcus species was used as a template in a standard PCR: P. micros (ATCC 33270, ATCC 23195), P. magnus NCTC 11804, P. anaerobius NCTC 11460, $P$. asaccharolyticus NCTC 11461, P. prevotii NCTC 11806, P. tetradius ATCC 35098, P. productus NCTC 11829 and $P$. indolicus NCTC 11088. DNA extracted from each of the following oral species was also used as a template in the PCR assay: Prevotella intermedia ATCC 25611, Porphyromonas gingivalis ATCC 33277, Bacteroides forsythus ATCC 43037, Helicobacter pylori ATCC 43504, Actinobacillus actinomycetemcomitans ATCC 33384, Fusobacterium nucleatum ATCC 25586, Eikenella corrodens ATCC 23834, Streptococcus mutans ATCC 25175 and Staphylococcus aureus ATCC 12600. PCR products were obtained with the two strains of $P$. micros but not with any other species tested (data not shown), thus confirming the specificity of the primers used in the PCR assay.

\section{PCR detection of P. micros in clinical samples}

The P. micros PCR assay was applied to the detection of this bacterial species in subgingival plaque samples from adult periodontitis patients and pus samples from subjects with acute dento-alveolar abscesses. P. micros DNA was detected by PCR in $19(28 \%)$ of the 68 samples analysed. Eleven (61\%) of 18 patients harboured $P$. micros DNA in at least one analysed site. Twenty (71\%) of 28 pus samples analysed (one per subject) contained $P$. micros DNA. Figs. $1 \mathrm{a}$ and $\mathrm{b}$ show representative results obtained with PCR to detect $P$. micros DNA in subgingival plaque samples and pus samples, respectively.

\section{Confirmation of PCR product specificity}

To confirm that successfully amplified products were derived from $P$. micros, PCR products were digested with the restriction endonuclease $R s a \mathrm{I}$, which gives a restriction profile unique to $P$. micros and, therefore, allows its distinction from other closely related Peptostreptococcus species. Digestion of PCR products obtained from $P$. micros gave DNA fragments with predicted sizes of 504, 261, 183 and 126 bp (Fig. 2). A further confirmatory digestion with HinfI yielded fragment sizes of 388, 312, 234 and 140 bp (Fig. 2). All PCR products gave restriction patterns with both $R s a \mathrm{I}$ and HinfI that were expected for P. micros.

Four PCR products were cloned into the pCR2.1-TOPO plasmid and four recombinant clones obtained from each cloned product were sequenced. The DNA sequence data confirmed that all 16 recombinant clones sequenced were derived from $P$. micros, thereby further demonstrating the specificity of the PCR assay.

\section{Discussion}

The purpose of this study was to design and implement a novel, direct PCR assay for the specific detection of P. micros DNA in clinical samples. Current methods for identification of this organism are heavily reliant on traditional microbiological culture and biochemical analyses. P. micros is commonly identified on the basis of colony morphology, oxygen tolerance and Gram's staining characteristics, followed by analysis of its enzymic activities (API ZYM, Rapid ID 32A) and its capacity to hydrolyse amino acid and phosphate substrates (RapID ANA II) [5, 18]. A selective and differential medium has been described that facilitates the primary isolation of $P$. micros from clinical samples which is based upon a Columbia CNA agar, supplemented with glutathione and lead acetate [15], that is selective for gram-positive cocci. When grown on this 
a

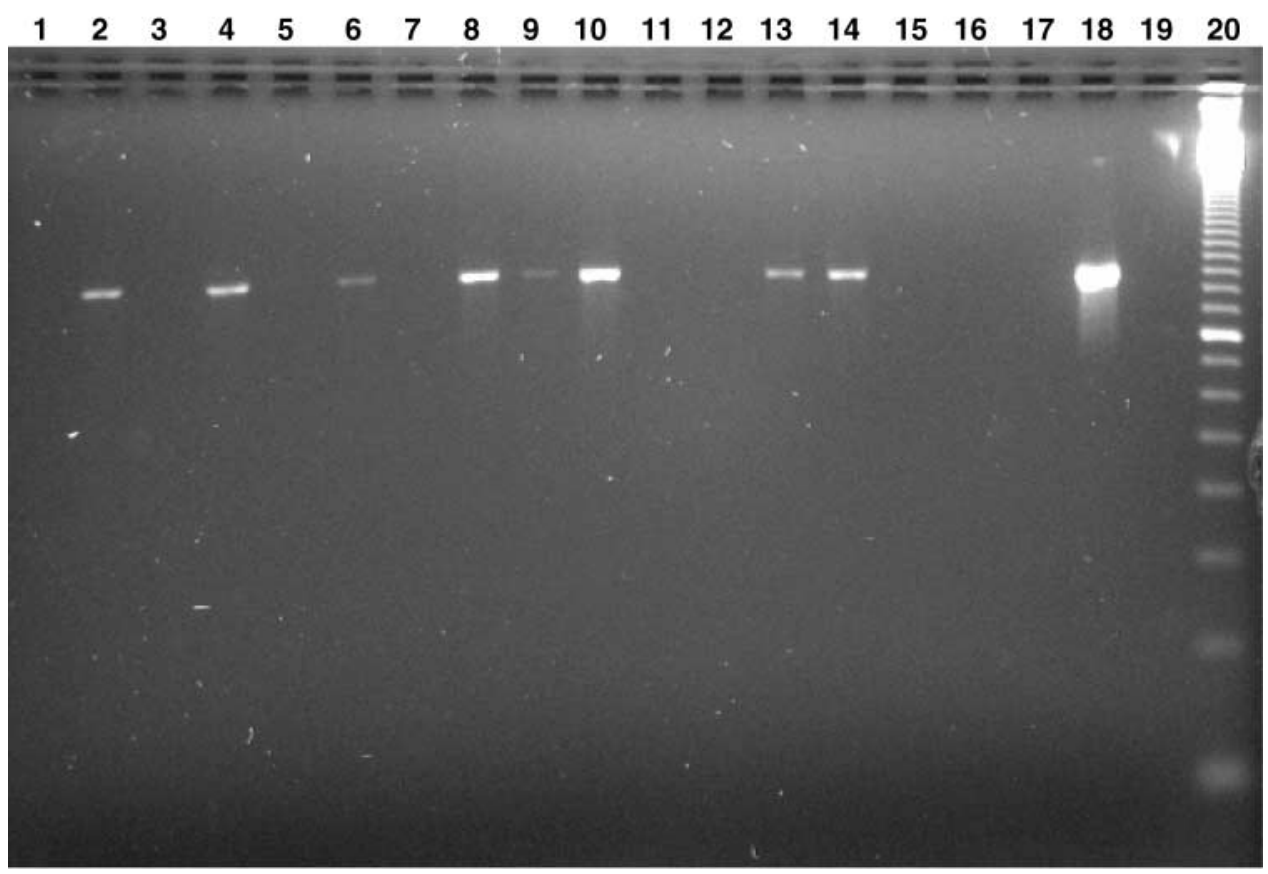

b

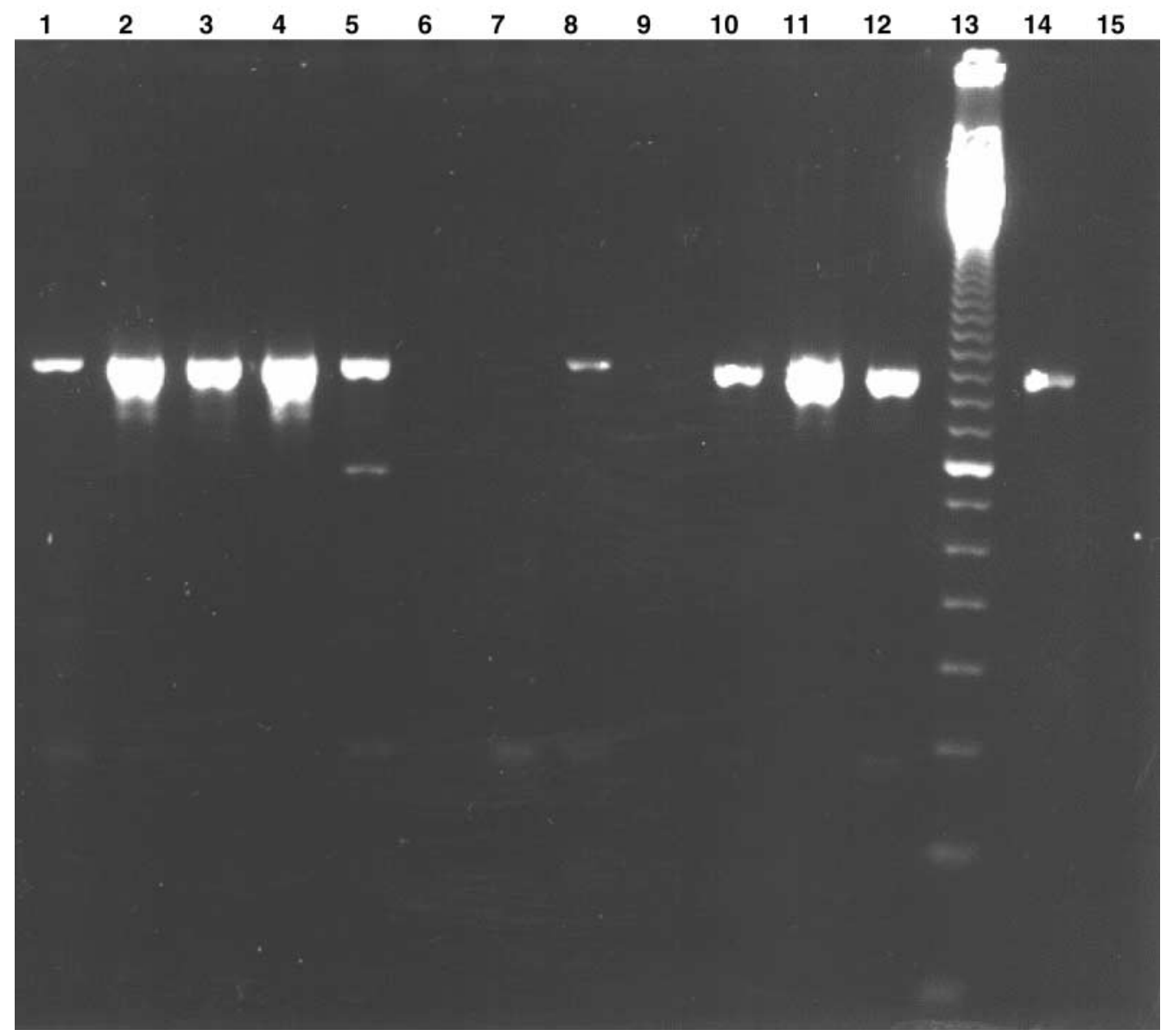

Fig. 1. Electrophoresis on agarose $2 \%$ gels of PCR products obtained from analysis of clinical samples for $P$. micros DNA. (a) Detection of P. micros DNA in subgingival plaque samples: lanes 1-17, subgingival plaque samples; 18 , positive control; 19, negative control; 20, 100-bp DNA ladder. (b) Detection of P. micros DNA in pus samples: lanes 1-12, pus samples; 13, 100-bp DNA ladder; 14, positive control; 15, negative control. A positive PCR result is indicated by the presence of a 1074-bp product. 


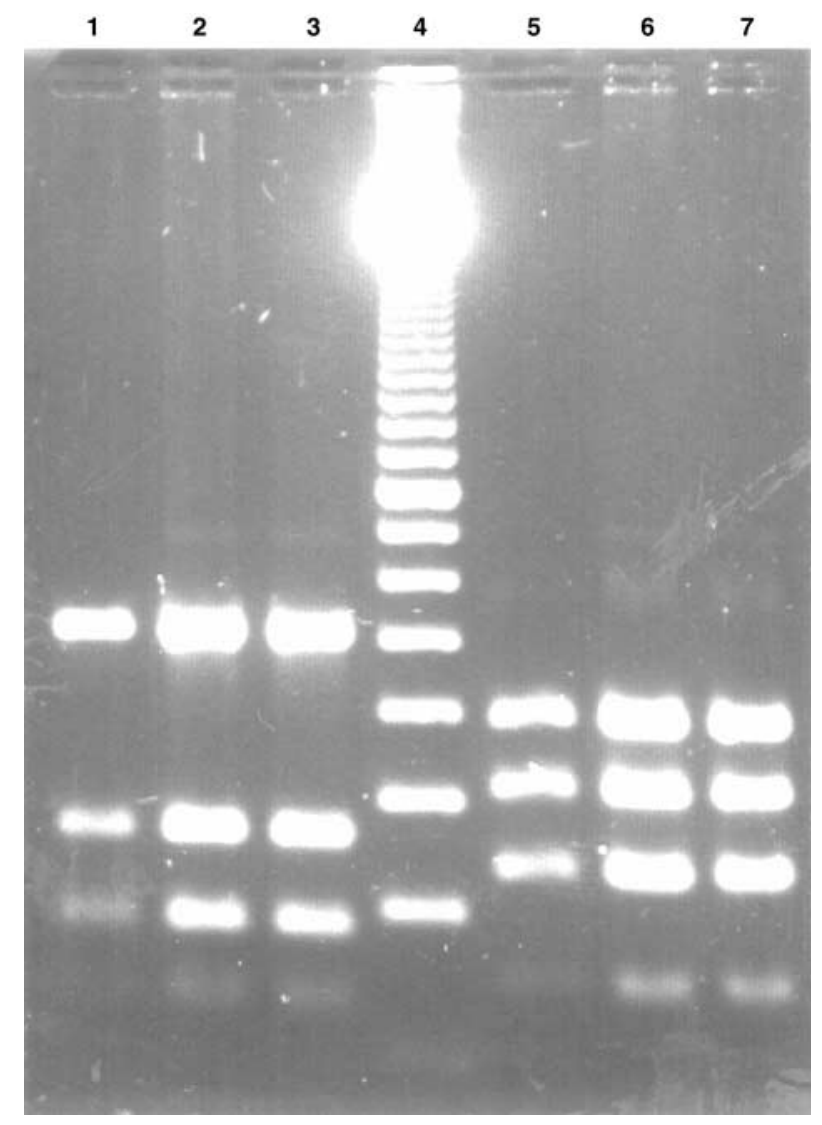

Fig. 2. Electrophoresis on agarose $2 \%$ gel of 1074-bp $P$. micros PCR products after digestion with restriction endonucleases RsaI and HinfI. Lanes $\mathbf{1}$ and 2, clinical samples, RsaI; 3, P. micros ATCC 33270, RsaI: 4, 100bp DNA ladder; 5 and 6, clinical samples, HinfI; 7, $P$. micros ATCC 33270, HinfI.

medium, P. micros utilises the reduced form of glutathione to form $\mathrm{H}_{2} \mathrm{~S}$, which reacts with lead acetate to produce a black precipitate that is clearly visible below $P$. micros colonies.

Whilst these methods have been of significant value, their usefulness is limited by the fact that results obtained are often ambiguous, primarily due to the emergence of phenotypically atypical strains which may differ in their biochemical characteristics. Furthermore, traditional identification methods are time-consuming, labour-intensive and expensive. PCR offers an alternative means of bacterial identification that overcomes these limitations. PCR is able to detect phenotypically divergent strains and is a rapid, highly specific and relatively inexpensive identification method.

In the present study, PCR primers were developed that specifically targeted the 16S rRNA gene of P. micros. The PCR assay successfully identified P. micros DNA in subgingival plaque from patients with adult periodontitis and in pus aspirates from patients with acute dento-alveolar abscesses. An elevated presence of $P$. micros in subgingival samples from patients with periodontal disease has been demonstrated previously by culture methods $[4,5]$. In the study of Rams et al. [5], subgingival plaque samples from 907 patients with advanced adult periodontitis, 127 with early-onset periodontitis and 12 with localised juvenile periodontitis were analysed for the presence of P. micros. It was found in $58-63 \%$ of samples analysed in these patient groups. The present study detected P. micros DNA by PCR in the subgingival plaque of 11 (61\%) of 18 adult periodontitis patients, a similar figure to the $63 \%$ patient positivity rate reported when culture methods were used for detection of P. micros [5]. An even higher prevalence of $P$. micros in the subgingival plaque of adult periodontitis patients has been reported, with $112(91 \%)$ of 123 patients shown to harbour the organism as demonstrated by culture methods [19]. The gingival immune response to periodontal pathogens in juvenile periodontitis patients has been examined by a gingival explant culture system, with local $\operatorname{IgG}$ levels to $P$. micros shown to be elevated in these patients compared with healthy controls [20].

In a study investigating the associations between microbial species in dental root canal infections $P$. micros was the most prevalent organism, being detected by culture in $22(34 \%)$ of 65 infected human root canals [21]. In the same study, a positive association was found between $P$. micros and Pr. intermedia, an association that has also been demonstrated in subgingival plaque [22]. The present study detected $P$. micros DNA by PCR in $20(71 \%)$ of 28 pus aspirates from acute dento-alveolar abscesses, which are a sequel to root canal infection. IgG, $\operatorname{IgM}$ and $\operatorname{IgA}$ antibodies have been found against several micro-organisms that are present in human peri-apical lesions, with IgG levels for P. micros being significantly high [23].

In conclusion, a novel PCR assay for the specific and direct detection of $P$. micros DNA in clinical samples has been developed and applied. PCR detection of $P$. micros DNA in subgingival plaque of adult periodontitis patients and in pus aspirates from acute dentoalveolar abscesses confirms $P$. micros as a putative pathogen in these lesions. The use of this PCR assay as a rapid, more reliable alternative to conventional culture and biochemical methods for identification of P. micros in clinical samples is proposed.

\section{References}

1. Neut C, Lesieur V, Romond C, Beerens H. Analysis of grampositive anaerobic cocci in oral, fecal and vaginal flora. Eur $J$ Clin Microbiol 1985; 4: 435-437.

2. Moore WEC, Holdeman LV, Smibert RM et al. Bacteriology of experimental gingivitis in young adult humans. Infect Immun 1982; 38: $651-667$.

3. Dzink JL, Socransky SS, Haffajee AD. The predominant cultivable microbiota of active and inactive lesions of destructive periodontal diseases. J Clin Periodontol 1988; 15: 316-323.

4. Moore WEC, Moore LH, Ranney RR, Smibert RM, Burmeister JA, Schenkein HA. The microflora of periodontal sites showing 
active destructive progression. J Clin Periodontol 1991; 18: 729-739.

5. Rams TE, Feik D, Listgarten MA, Slots J. Peptostreptococcus micros in human periodontitis. Oral Microbiol Immunol 1992; 7: $1-6$.

6. Brook I, Grimm S, Kielich RB. Bacteriology of acute periapical abscess in children. J Endod 1981; 7: 378-380.

7. Williams BL, McCann GF, Schoenknecht FD. Bacteriology of dental abscesses of endodontic origin. J Clin Microbiol 1983; 18: $770-774$

8. Newman MG, Sims TN. The predominant cultivable microbiota of the periodontal abscess. J Periodontol 1979; 50: 350-354.

9. Mitchelmore IJ, Prior AJ, Montgomery PQ, Tabaqchali S. Microbiological features and pathogenesis of peritonsillar abscesses. Eur J Clin Microbiol Infect Dis 1995; 14: 870-877.

10. Brook I. Recovery of anaerobic bacteria from clinical specimens in 12 years at two military hospitals. J Clin Microbiol 1988; 26: $1181-1188$.

11. Sullivan PM, Johnston RC, Kelley SS. Late infection after total hip replacement, caused by an oral organism after dental manipulation. A case report. J Bone Joint Surg 1990; 72A: $121-123$.

12. Brook I. A 12 year study of aerobic and anaerobic bacteria in intra-abdominal and postsurgical abdominal wound infections. Surg Gynecol Obstet 1989; 169: 387-392.

13. Kremer BHA, Magee JT, van Dalen PJ, van Steenbergen TJM Characterization of smooth and rough morphotypes of Peptostreptococcus micros. Int J Syst Bacteriol 1997; 47: 363-368.

14. van Dalen PJ, van Deutekom-Mulder EC, de Graaff J, van Steenbergen TJM. Pathogenicity of Peptostreptococcus micros morphotypes and Prevotella species in pure and mixed culture. J Med Microbiol 1998; 47: 135-140.
15. Turng B-F, Guthmiller JM, minah GE, Falkler WA. Development and evaluation of a selective and differential medium for the primary isolation of Peptostreptococcus micros. Oral Microbiol Immunol 1996; 11: 356-361.

16. Gmur R, Thurnheer T. Monoclonal antibodies for the rapid identification in clinical samples of Peptostreptococcus micros and Actinobacillus actinomycetemcomitans serotypes a, d, and e. Med Microbiol Lett 1996; 5: 335-349.

17. Riggio MP, Macfarlane TW, Mackenzie D, Lennon A, Smith AJ, Kinane D. Comparison of polymerase chain reaction and culture methods for detection of Actinobacillus actinomycetemcomitans and Porphyromonas gingivalis in subgingival plaque samples. J Periodont Res 1996; 31: 496-501.

18. Ng J, Ng L-K, Chow AW, Dillon J-AR. Identification of five Peptostreptococcus species isolated predominantly from the female genital tract by using the Rapid ID 32A system. J Clin Microbiol 1994; 32: 1302-1307.

19. van Dalen PJ, van Winkelhoff AJ, van Steenbergen TJM. Prevalence of Peptostreptococcus micros morphotypes in patients with adult periodontitis. Oral Microbiol Immunol 1998; 13: 62-64.

20. Hall ER, Martin SA, Suzuki JB, Falkler WA. The gingival immune response to periodontal pathogens in juvenile periodontitis. Oral Microbiol Immunol 1994; 9: 327-334.

21. Sundqvist G. Associations between microbial species in dental root canal infections. Oral Microbiol Immunol 1992; 7: $257-262$.

22. Socransky SS, Haffajee AD, Dzink JL, Hillman JD. Associations between microbial species in subgingival plaque samples. Oral Microbiol Immunol 1988; 3: 1-7.

23. Kettering JD, Torabinejad M, Jones SL. Specificity of antibodies present in human periapical lesions. $J$ Endod 1991; 17: 213-216. 